\title{
Ediciones propagandísticas españolas en Argentina durante la Guerra Civil y el primer franquismo: la labor de José Ignacio Ramos
}

Propagandistic Spanish Publishing in Argentina during the Civil War and first

Francoism: the work of José Ignacio Ramos

\section{FRANCISCA MONTIEL RAYO • Francisca.Montiel@uab.cat GEXEL/CEFID/UNIVERSITAT AUTÒNOMA DE BARCELONA (ESPAÑA)}

Miembro fundador del Grupo de Estudios del Exilio Literario (GEXEL), se doctoró en la Universitat Autònoma de Barcelona con la tesis Esteban Salazar Chapela en su época: obra literaria y periodística (1923-1939). Catedrática de Lengua y Literatura Españolas de Enseñanza Secundaria y profesora asociada de Literatura Española de la Universitat Autònoma de Barcelona, ha impartido cursos sobre la literatura del exilio republicano de 1939 y ha participado en diversos congresos internacionales sobre el mismo tema. Además de al estudio de la obra de Esteban Salazar Chapela, ha consagrado algunas de sus investigaciones a la producción de Segundo Serrano Poncela y de Max Aub, entre otros autores, así como a las publicaciones periódicas aparecidas en el destierro y a la correspondencia que intercambiaron los protagonistas de la diáspora.

RECIBIDO: 16 de diciembre de 2015

ACEPTADO: 22 de mayo de 2016

RESUMEN: Desde su nombramiento como agregado de Prensa de la representación oficiosa del Gobierno de Burgos en Argentina a principios de 1937, José Ignacio Ramos desarrolló una intensa actividad propagandística en aquel país que lo vinculó al mundo el libro, convirtiéndolo en editor ocasional, tanto durante la Guerra Civil como en los primeros años del franquismo. De acuerdo con las directrices de actuación establecidas por el régimen, Ramos ignoró la actividad editorial de las empresas promovidas por exiliados republicanos y silenció la publicación de sus obras. En defensa de los intereses gubernamentales participó asimismo en el debate sobre el problema de la venta de libros entre España y Argentina que se suscitó en aquellos años.

PALAbras Clave: José Ignacio Ramos, propaganda, Guerra Civil, franquismo, editoriales.
ABSTRACT: Since he was appointed attaché in the unofficial legation of the Burgos Government in Argentina at the beginning of 1937, José Ignacio Ramos carried out an intense activity in propaganda in that country which led him to links with the book industry. This made him occasional publisher during the Civil War and in the first years of postwar Francoism. According to the guidelines set by the regime, Ramos ignored the publishing activity of the companies promoted by republican exiles and silenced the publishing of their works. In defense of the Government's interests, he also took part in the debate on the book trade between Spain and Argentina which arose in those years.

KEY WORDS: José Ignacio Ramos, propaganda, Civil War, Francoism, Publishing companies.

\section{Montiel Rayo, Francisca. "Ediciones propagandísticas españolas en Argentina durante la Guerra Civil y el primer franquismo". Kamchatka. Revista de análisis cultural 7 (Junio 2016): 35-57}

DOI: 10.7203/KAM.7.7682 ISSN: 2340-1869 
Francisca Montiel Rayo. Ediciones propagandísticas españolas...

La convicción del Gobierno de Burgos de que, además de vencer con las armas en los frentes de batalla, debía utilizar en el exterior "el efecto persuasivo y legitimador de la maquinaria propagandística" (Moreno, 2007: 266) lo llevó a crear, poco después de la sublevación, oficinas de prensa y propaganda en varios países, prioritariamente en aquellos

donde estuviesen establecidos gobiernos de centro-derecha y donde los grupos católicos ejerciesen un peso destacado. De esta manera podrían valerse del apoyo de las instituciones eclesiásticas y políticas de los mismos para hacer llegar su voz o palabra a todos los recodos de esas sociedades extranjeras (Moreno, 2007: 267).

Buena parte de esas condiciones se daban en Argentina, país en el que la población -incluida la colonia española, la más numerosa de las que se asentaba entonces fuera del país- apoyaba mayoritariamente a la República. Para contrarrestar dicha ayuda -y la que recibía la España leal en otros territorios del continente americano- los sublevados decidieron que era conveniente poner en marcha una oficina en Buenos Aires, cuya dirección le fue encomendada a Juan Pablo de Lojendio, cónsul de segunda en Niza hasta el inicio de la Guerra Civil, cuando, como tantos otros diplomáticos que se declararon partidarios de la rebelión, fue separado del cuerpo por el Gobierno de la República (Viñas, 2010: 434). Tras su llegada a la capital argentina a finales de diciembre de 1936, Lojendio puso en marcha la representación oficiosa, un trabajo para el que contó desde el primer momento con la colaboración de José Ignacio Ramos, que fue nombrado agregado de Prensa y Propaganda del Gobierno de Burgos en Argentina el 28 de enero de 1937. Dos días después era designado para desempeñar un puesto análogo en la Jefatura Nacional de Falange en aquel país (Moreno, 2008: 589).

Fundador de las JONS junto a su amigo Ramiro Ledesma Ramos -según aseguró en Biografía de mi entorno (1984: 122)-, Ramos se había refugiado en la Embajada de Argentina en Madrid poco después del estallido de la Guerra Civil, lo que le permitió salir de la España republicana e iniciar una trayectoria profesional en el país austral -de donde era natural su esposa- que lo vincularía de por vida con el franquismo. En los primeros años de su actividad política, que se prolongó hasta la transición democrática, las labores de propaganda que realizó lo pusieron en contacto con el mundo de la edición. Su trabajo en la Oficina de Prensa y Propaganda de la Representación de la España sublevada en Argentina primero y en la Embajada de España en ese país después -durante los primeros años de vida de la legación- se desarrolló en el contexto de la denominada "edad de oro de la edición argentina", "periodo de máxima y explícita conflictividad entre editores argentinos y españoles en el que Buenos Aires ocupa a su inicio y abandona a su final -[...] por motivos políticos y económicos- el epicentro de la actividad editorial en lengua española” (Larraz, 2014: 128). 
Francisca Montiel Rayo. Ediciones propagandísticas españolas...

\section{Ediciones OPYPRE y Editorial Difusión}

Advertido de que no podría contar con financiación alguna llegada desde España, Lojendio creó y dirigió la representación oficiosa del Gobierno rebelde en Argentina con el apoyo logístico y económico de un grupo de españoles residentes en el país que sufragó los gastos de la Oficina aportando mensualmente una elevada cuota. Sin esta iniciativa, promovida y ejecutada por Rafael Vehils, su constitución no hubiera sido posible (Quijada, 1991: 222)1. Vehils, que había sido diputado por la Lliga Regionalista que lideraba Francesc Cambó entre 1918 y 1919, había asumido en 1931 la dirección de la Compañía Hispano-Americana de Electricidad (CHADE), cargo que ocupó hasta 1936, cuando, obligada a nacionalizarse, la empresa creada con capital español pasó a denominarse Compañía Argentina de Electricidad (CADE). Entre 1932 y 1933 había sido el máximo responsable de la Cámara Española de Comercio de Argentina, puesto desde el que se enfrentó al Gobierno de la República para tratar de impedir que la junta pasara a depender del Ministerio de Economía, como el Ejecutivo pretendía. Al estallar la contienda, solo esta institución española en Argentina realizó una “declaración pública, oficial y unívoca de apoyo" al Gobierno de Burgos, al que reconoció "como única autoridad legítima de España” (Quijada, 1991: 114). Andreu Bausili -otro hombre de Francesc Cambó-, miembro al igual que Vehils del grupo que financió desde su creación la Oficina de Prensa y Propaganda de la Representación de la España de Franco en Buenos Aires (Quijada, 1991: 226)², lo sucedió en la dirección de la Compañía de Electricidad de Argentina -que presidía Cambó- en 1936, y fue el máximo responsable de la Cámara de Comercio a partir del mes de agosto de 1938.

Gracias a sus aportaciones económicas y a las de otros adinerados residentes en Buenos Aires ${ }^{3}$, la Oficina inició sus actividades propagandísticas -su principal razón de ser- utilizando para ello todos los medios que tuvo a su alcance. Además de la emisión de espacios radiofónicos (Ramos, 1984: 289), de la proyección de documentales sobre la marcha de la guerra o sobre la vida en la retaguardia (Quijada, 1991: 225) y de la celebración de charlas y de otros actos públicos, la representación oficiosa divulgó "un Boletín de Orientación e Información y unas Notas Españolas realizados a partir de la

\footnotetext{
1 "Vehils [...] se encargó de reunir a un conjunto de compatriotas destacados de la comunidad que acordaron una subvención mensual por persona de 200 pesos. Entre todos recaudaban la suma de 6000 pesos” (Quijada, 1991: 222).

2 Tanto Vehils como Bausili, así como otros miembros de la CHADE, ya habían entregado grandes sumas de dinero al Vizconde de Ocaña, único representante de la Junta de Burgos en Buenos Aires, antes del establecimiento de la Oficina de Prensa y Propaganda de la Representación de España (Riquer, 1997: 185).

${ }^{3}$ Además de los ya mencionados Vehils y Bausili, la lista completa de los primeros cotizantes estaba integrada por Francisco y Antonio Boo, Amador Fernández, Antonio Esquioiz, Alfredo Calleja, Carlos Rossi, Conde de Guadalhorce, Rafael Delgado Benítez, García y Cía., Maura y Coll, Ignacio Rodrigo, Francisco Muñoz, M. Adúriz y Cía., Bernabé Pérez Ortiz, Ramiro Rodríguez Barro. Baldomero Villaamil, Manuel Escasany, Timoteo Balbín, José Mouriño, Vicente Vercher, Florentino y Faustino Fano, Pablo Masllorens y José Villamarín (Pérez Ortiz, 1941: 132; citado por Quijada, 1991: 226).
} 
documentación suministrada desde Salamanca" (Delgado, 1992: 121). La delegación de Buenos Aires seguía así las principales directrices señaladas por la Oficina de Prensa y Propaganda de París, una de las primeras agencias que se abrieron en el extranjero por iniciativa de algunos políticos de la Lliga Regionalista (Moreno, 2007: 267), partido que desde 1933 había pasado a denominarse Lliga Catalana.

Organizada por Francesc Cambó - quien confiaba "en que los catalanistas conservadores tendrían algún papel destacado en el nuevo régimen", lo que "les permitiría realizar una tarea de 'salvación' nacional y de reagrupación de los mismos" (Moreno, 2007: 276)-, su hombre clave fue el mallorquín Joan Estelrich -uno de los principales ideólogos de la Lliga-, que ejerció el cargo de director de publicaciones. En cumplimiento de su misión, Estelrich ideó un ambicioso plan -no circunscrito únicamente a territorio francés- al que se refirió, meses después de haber sido puesto en marcha, en un informe fechado el 6 de julio de 1937:

Para mayor eficacia en la divulgación de nuestras publicaciones, consideramos indispensable que parta de París su irradiación en Francia y en los distintos países, y que se centralicen aquí todas las gestiones editoriales de todos los países, referente a las publicaciones concebidas y escritas aquí, sin perjuicio, claro está, de que se actúe, en otros países de acuerdo con las Oficinas de Propaganda que en ellas existan, y, sin perjuicio, además, de que estas puedan publicar por su cuenta otras publicaciones o acomodar las nuestras a las necesidades locales (Massot, 1998: 179).

Las ediciones en lengua española de "las publicaciones concebidas y escritas" en Francia debían realizarse en Buenos Aires, razón por la que en abril de 1937 Estelrich se puso en contacto con su correligionario Andreu Bausili, a quien le fue remitiendo los originales que debían aparecer en América y a quien le indicó también cómo debían realizarse la edición -a menudo una versión corregida y revisada de la francesa- y la difusión de los textos. La correspondencia mantenida entre ambos a propósito de $L a$ persecución religiosa en España, segundo título editado por la Oficina establecida en Francia, da cuenta de cuáles fueron los procedimientos que se siguieron para publicar en Argentina las obras que salían de París.

La persecución religiosa en España no era, le aseguró Estelrich a Bausili en la carta que le envió el 13 de abril de 1937, un volumen solo de propaganda, sino un libro histórico que él no podía firmar -como sucedió con otros títulos promovidos por Prensa y Propaganda- por temor a las represalias que se pudieran tomar contra sus familiares, residentes en la España republicana (Massot, 1998: 85). La edición argentina, de la que se podían tirar en opinión de Estelrich al menos 5000 ejemplares, debería venderse -no regalarse- al precio de 2 o de 2,50 pesos, prosiguió. A continuación, el director de publicaciones de la Oficina de París le proponía a Bausili que gestionara la edición en español con Espasa-Calpe -cuyos directores eran buenos amigos de Estelrich-, casa a la que únicamente debería exigirle que reservara un $12 \%$ del precio de venta en concepto de derechos de autor. Si esa editorial no 
quería hacerse cargo de la edición, Estelrich sugería que esta se realizara por cuenta de la Oficina de Prensa y Propaganda, y que Espasa-Calpe u otro editor o librero se ocupara de la venta y de la distribución de los ejemplares, lo que les reportaría un 50 o un 55\% del precio de la tirada (Massot, 1998: 86).

No se sabe si Bausili realizó en Espasa-Calpe las gestiones que le indicó su interlocutor, pero el contenido de una nueva carta enviada por Estelrich -fechada en esta ocasión el 29 de julio de 1937permite deducir que Bausili le había consultado previamente si era posible que se hiciera cargo de la edición la Editorial Difusión (Massot, 1998: 86). El consentimiento otorgado por Estelrich permitió que a partir de entonces las ediciones de la Oficina de Prensa y Propaganda de la Representación de España en Buenos Aires vieran la luz con su propio sello -OPYPRE, siglas del nombre de la Oficina- o con el de Editorial Difusión, empresa que inició sus actividades en 1937 -el mismo año en el que se pusieron en marcha las ediciones de la Oficina de Prensa y Propaganda de la Representación de España en Buenos Aires-. Difusión había sido creada por Luis Luchía Puig, fundador de otras empresas -entre las que cabe mencionar La Novela del Día y las editoriales Bayardo y Propaganda Moderna (Fabris, 2013: 155)- en las que colaboró siempre -de una forma u otra- su hermano Agustín, director de la revista Aconcagua, de la que José Ignacio Ramos había sido "corresponsal honorario" en España antes del inicio de la Guerra Civil (Ramos, 1984: 122).

Esta vinculación del agregado de Prensa y Propaganda con los Luchía Puig tal vez permitió que se iniciaran los contactos de la representación oficiosa con la nueva editorial, pero todo parece indicar que su participación en la preparación de las ediciones y en el establecimiento de acuerdos comerciales con Difusión fue -como la del máximo responsable de la Oficina-secundaria, razón por la que no alude a ella en su biografía. Juan Pablo de Lojendio se hallaba por aquel entonces centrado en las charlas propagandísticas que daba periódicamente en localidades argentinas y de los países vecinos, y Ramos, valiéndose de sus buenos contactos y de su estrecha relación con algunos sectores de poder argentinos, trabajaba sin descanso para lograr introducir las tesis y los argumentos de los sublevados en los diarios del país (Moreno, 2008: 560). Las gestiones editoriales quedaron así en manos de Andreu Bausili -y tal vez también en las de Rafael Vehils-, que contaba con la plena confianza de Estelrich, tenía cierta experiencia en el sector editorial y era uno de los miembros del grupo de españoles que financiaba la Oficina y, por tanto, también las publicaciones que esta se proponía editar: libros y folletos que vieron la luz en no pocas ocasiones con el sello de Difusión -y no con el de la Oficina de Prensa y Propaganda-, tal como recomendaba Estelrich, quien en el informe anteriormente citado recordaba, al referirse a los títulos en preparación, que, "por su naturaleza”, debían "tener un carácter privado, en el grado que exija, para cada caso, la eficacia de la propaganda”, en tanto que otros textos, como proclamas o discursos, debían poseer un "carácter totalmente oficial” (Massot, 1998: 178). 
La consulta del catálogo electrónico de la Biblioteca Nacional de Argentina revela que, además de los libros que aparecieron con su sello a instancias de la OPYPRE, en su primer año de vida la Editorial Difusión -sita en el número 1859 de la calle Tucumán- solo dio a la luz títulos -volúmenes en todos los casos de muy pocas páginas- de propaganda anticomunista ${ }^{4}$ de contenido religioso ${ }^{5}$, textos que fueron escritos a menudo por conocidos miembros de la Iglesia Católica, lo que no solo abunda en lo ya sabido, el decisivo apoyo que esta prestó "en la labor de divulgación de los principios del Nuevo Estado" (González Calleja, 2001: 225) ${ }^{6}$, sino que permite pensar que Bausili y los miembros de la Oficina de Prensa y Propaganda de la Representación de la España Nacional en Buenos Aires decidieron editar buena parte de sus publicaciones a través de una nueva editorial creada $a d$ hoc -o tal vez se aprovechó la circunstancia de que el sello iba a iniciar su andadura en aquel momento para proponerles a sus responsables un convenio de colaboración-, una editorial que presentaba toda la apariencia de una empresa privada ajena a la delegación de la España sublevada.

Los libros aparecidos en 1938, casi el doble de los publicados en 1937, ratifican lo dicho anteriormente. Editorial Difusión continuó publicando títulos sobre teología, doctrina y moral católicas, escritos varios de ellos por monseñor Franceschi y por el jesuita vasco José Antonio de Laburu. También vieron la luz dos nuevos textos anticomunistas, obras en esta ocasión de José H. Ledit. Difusión divulgó asimismo un pequeño volumen de 46 páginas titulado Autodefensa de Judas y de Pilatos: un libro al revés de todos, de Paul Claudel, autor del poema-prefacio que se situó al frente de La persecución religiosa en España, la obra con la que la casa editora había iniciado el acuerdo de colaboración con la OPYPRE?

En dicho convenio la Oficina le cedió todos los derechos de este libro a Difusión -como sucedería también con las siguientes ediciones- a cambio de que hiciera una gran tirada a un precio económico ${ }^{8}$,

\footnotetext{
${ }^{4}$ La avalancha comunista, de Rómulo Amadeo; ¿Puede triunfar el comunismo en Argentina?, del coadjutor salesiano Carlos Conci, y La amada libertad del Partido Comunista, del jesuita francés P. Croizier.

${ }^{5}$ Respuestas a la conferencia y artículos del Dr. Lisandro de la Torre, de monseñor Gustavo Franceschi; Por mi Dios y por mi Patria, de monseñor Andrés Calcagno; El ideal cristiano del matrimonio, del canónigo Cardyn, y Tu misa y tu vida, del abate G. Dutil.

${ }^{6}$ Publicaciones como la revista bonaerense Criterio, dirigida por monseñor Gustavo Franceschi, "se declararon desde el primer momento a favor del bando rebelde" (González Calleja, 2001: 225).

${ }^{7}$ Los libros publicados en 1939, más de treinta, ratifican el carácter confesional de la editorial, que continuó publicando títulos sobre religión en los años siguientes, en los que dejaron de difundir textos sobre España. Con un éxito creciente desde su fundación, la editorial Difusión alcanzó sus mejores resultados comerciales en la década de los cuarenta.

${ }^{8}$ En carta fechada el 29 de julio de 1937, Estelrich le comunicaba a Bausili que tenía una propuesta de la casa Ercilla de Santiago de Chile para publicar su libro pagando derechos de autor. Todo estaba, por tanto, por decidir, pero le advertía de que si Difusión quería hacerse cargo también de la segunda edición tendría que hacer una tirada corta de la primera. Si no le interesaba una segunda edición, la tirada de la primera debería ser grande. "Decidiu vosaltres mateixos", concluyó (Massot, 1998: 87).
} 
llegándose a distribuir en toda la América española miles de ejemplares ${ }^{9}$. De La justicia revolucionaria en España, de Joaquim Reig, colaborador de la Oficina de París que ocultó su nombre bajo el seudónimo Juan de Castilla, se hizo una primera edición con el sello de OPYPRE ${ }^{10}$. La segunda apareció editada por Difusión, empresa que publicó asimismo Los intelectuales españoles ante la revolución y la guerra, del escritor Alberto Insúa, cuya identidad fue omitida utilizando el mismo seudónimo -Juan de Castilla- que había servido para proteger a Joaquim Reig ${ }^{11}$. Joan Estelrich, que no había firmado La persecución religiosa en España por los motivos ya mencionados, sí consignó su nombre en La cuestión vasca y la guerra civil española, que vio la luz también en Difusión.

Editados por la representación oficiosa del Gobierno de Burgos con su propio nombre, aparecieron también en aquel año de 1937 otros dos textos llegados desde París: Argumento de la nueva España: los 26 puntos de Falange Española Tradicionalista y de las JONS -traducción española de Les bases de la nouvelle Espagne- y Un año de guerra: lo que ha pasado durante un año en la retaguardia y en los frentes de batalla de España, cuya primera edición había visto la luz sin nombre de editorial.

Por iniciativa propia, la Oficina de Prensa y Propaganda de Buenos Aires divulgó en 1937 -como todos los títulos anteriormente citados- el volumen colectivo España roja, uno de cuyos autores era el jesuita gaditano Francisco García Alonso, cuyo testimonio sobre el inicio de la Guerra Civil -Mis dos meses en la prisión de Málaga- lo había convertido ya en un personaje célebre en la España de Franco. El librito contó con dos ediciones, una de OPYPRE y otra de Editorial Difusión. Con su sello la representación oficiosa dio a la luz España y su revolución, del periodista Francisco Casares, nombrado en diciembre de 1937 secretario general de la Asociación de la Prensa de Madrid, cargo de una Junta Directiva que iniciaría su labor "en su día"12; esto es, cuando finalizara, con el triunfo de la España nacional, el conflicto. Del mismo modo aparecieron los Discursos de Juan Pablo de Lojendio en Montevideo y Por el amor de España: petitorio en seis romances y epílogo en prosa, de Eduardo Marquina.

\footnotetext{
${ }^{9}$ A finales de 1937 el libro había alcanzado un volumen de ventas de unos 20.000 ejemplares contando los vendidos en Francia, Inglaterra y, sobre todo, en América (Massot, 1998: 84-85).

${ }^{10}$ Por indicación de Estelrich, este título -el primero que había visto la luz en Francia- se publicó siguiendo el mismo procedimiento utilizado con La persecución religiosa en España (Massot, 1998: 106).

${ }^{11}$ Curiosamente, ese fue también el seudónimo que utilizó el escritor republicano Arturo Barea, exiliado en Gran Bretaña, para firmar sus colaboraciones radiofónicas en la $B B C$.

12 "La Junta Directiva de la Asociación de la Prensa de Madrid". $A B C$ (8-12-1937): 12. Francisco Casares pudo coincidir con José Ignacio Ramos en la legación argentina de Madrid al iniciarse la Guerra Civil, donde ambos se ocultaron. Casares relató dicha experiencia en Argentina-España, 1936-1937 (Apuntes y recuerdos de un asilado en la Embajada Argentina de Madrid). Buenos Aires: Editorial Poblet (1937).
} 
En 1938 la delegación solo divulgó, con su propio pie de imprenta, un folleto que había sido publicado previamente en francés, Liberalismo y comunismo. Reflexiones sobre la revolución española, de Gregorio Marañón. Los causantes de la tragedia hispana: un gran crimen de los intelectuales españoles, del jesuita santanderino Constancio Eguía, vio la luz editado por Difusión, aunque es de suponer que su aparición contó con la participación de la OPYPRE. En esta drástica disminución del número de ediciones promovidas y financiadas por la Oficina de Prensa y Propaganda bonaerense - cambio que no se produjo en la misma medida en París- pudo influir el hecho de que en el mes de agosto de 1938 se dieran de baja de la comisión que financiaba la representación varios cotizantes, lo que obligó a los que permanecieron fieles al compromiso adquirido con Vehils a elevar las cuotas mensuales que venían aportando desde hacía más de un año de 200 a 300 pesos (Quijada, 1991: 222 y 195-198).

Cabe tener presente, además, que la Oficina de Prensa y Propaganda contaba desde finales de 1937 con un gasto fijo, la edición de las publicaciones periódicas que iniciaron su andadura entonces, publicaciones que sin duda requerían de una buena parte del presupuesto de la Oficina destinado a sufragar ediciones. Este cambio de política editorial -y, por tanto, de estrategia propagandística- varió también el reparto de responsabilidades que había existido hasta entonces. Andreu Bausili -y, tal como se ha indicado anteriormente, acaso también Rafael Vehils-, encargados durante 1937 de las ediciones sugeridas por París -de igual modo que sucedió con toda probabilidad con las que se promovieron en y desde Buenos Aires-, le dieron el relevo a José Ignacio Ramos, que se convirtió así en el máximo responsable de las publicaciones seriadas creadas por la Oficina. Tras aquella experiencia, Vehils y Bausili se embarcaron -a instancias del primero- en la que llegaría a ser una importante aventura editorial, la creación de Sudamericana, empresa fundada a finales de 1938 con la participación de otros empresarios e intelectuales argentinos y españoles a los que se sumaría muy pronto el librero y editor Antonio López Llausàs, miembro asimismo de Lliga Catalana que fue llamado para trabajar en la casa por Vehils, a quien no tardaría en desplazar, pues, "además de convertirse en propietario, asumió la dirección de la editorial hasta su muerte, producida en 1979, desluciendo el papel central que tuvo Vehils en el primer año de funcionamiento de Sudamericana" (Corte y Espósito, 2010: 279). Aunque no trascendió, la decisiva actuación de los fundadores de Sudamericana en la puesta en marcha y en el sostenimiento de las actividades propagandísticas llevadas a cabo por los sublevados en Buenos Aires durante la Guerra Civil resultaría determinante en el tratamiento que las autoridades españolas les habrían de dispensar en Argentina, tanto a ellos como a la editorial, en el futuro. 
Francisca Montiel Rayo. Ediciones propagandísticas españolas...

\section{Publicaciones periódicas}

La Oficina de Prensa y Propaganda editó, con su sello, dos publicaciones seriadas de las que, como ha sido dicho, fue responsable José Ignacio Ramos. La segunda en ver la luz fue La Ametralladora, edición sudamericana de la revista homónima creada por la Delegación del Estado para Prensa y Propaganda que había iniciado su andadura en Salamanca en los primeros meses de 1937. Dicha publicación se transformaría en la inmediata posguerra en la célebre revista La Codorniz (Llera, 2007: 126). El primer número de La Ametralladora, que se anunciaba como "la mejor revista humorística sobre la actuación de los leales a Moscú” (Quijada, 1991: 218), se publicó en Buenos Aires en noviembre de 193713, el mismo mes en el que Miguel Mihura asumió la dirección de la publicación salmantina, en la que introdujo el humorismo vanguardista que caracterizó a revistas de los años veinte e inicios de los treinta como Buen Humor, Gutiérrez o Muchas Gracias. De periodicidad mensual, La Ametralladora argentina, algunos de cuyos chistes antirrepublicanos se reprodujeron en la revista antisemita bonaerense Clarinada (Quijada, 1991: 219), dejó de publicarse en 1938 ${ }^{14}$.

Aunque no exenta de polémica en algunos momentos de su trayectoria, la revista Orientación Española. La voz autorizada de España para todos los españoles de la Argentina fue la empresa más duradera de cuantas impulsó la representación oficiosa de la España sublevada en Buenos Aires, y se considera también la publicación franquista más importante editada en aquel país (Moreno, 2008: 548). Creada y dirigida por José Ignacio Ramos (1984: 344), su número inaugural vio la luz en septiembre de 1937, el mismo mes en el que iniciaron su andadura dos publicaciones hermanas: el semanario Spain, editado por los Servicios de Prensa Española de Londres, y la publicación quincenal Occident, revista que ideó y dirigió en París Joan Estelrich, quien, ya iniciado 1938, se mostró satisfecho de haberle dado un formato de éxito, el de los semanarios de ideas que aparecían habitualmente en la capital francesa (Massot, 1998: 190). El proyecto concebido por Estelrich fue adoptado en Londres y en Buenos Aires, como había sucedido ya con los folletos y con los libros que salieron de la sede de Propaganda en París. Orientación Española, igual que Spain y Occident, cumplió con su principal objetivo, que era dar a conocer el Movimiento Nacional al gran público a través de la venta ordinaria de la publicación. Las tres revistas compartieron también las noticias y el material gráfico que les remitían desde España para que se confeccionaran las publicaciones. Inicialmente coincidieron en su estructura. La de Orientación Española incluyó, además de información sobre los frentes, reportajes, notas y réplicas en las que se contra-

\footnotetext{
${ }^{13}$ Tras la aparición de su primer número de La Ametralladora, José Ignacio Ramos solicitó el prescriptivo asiento de la publicación en el Registro Nacional de Propiedad Intelectual, según quedó consignado en el Boletín Oficial de la República Argentina del 10 de diciembre de 1937.

${ }^{14}$ La publicación contó, al menos, con cuatro entregas (González Grano, 2004: 468).
} 
Francisca Montiel Rayo. Ediciones propagandísticas españolas...

rrestaban los argumentos en favor de su causa divulgados por los republicanos (Moreno, 2008: 559), una sección denominada "Las armas y las letras (Revista de Libros)”. En sus páginas se divulgaron textos de escritores e intelectuales afectos a la sublevación entre los que cabe citar a Wenceslao Fernández Flórez, Eugenio Montes, José María Pemán, Manuel Machado, Pedro Laín Entralgo, Eugenio d’Ors, Antonio Tovar o Dionisio Ridruejo.

Financiada con el dinero que aportaba la comisión que sufragaba los gastos de la Oficina de Prensa y Propaganda desde su creación, la publicación de Orientación Española fue objeto de recelos y de críticas por parte de los miembros de Falange residentes en Argentina, que reclamaban para sí un mayor protagonismo, lo que le ocasionó "graves problemas a la Representación de la España Nacional, produciéndose frecuentes enfrentamientos con ella que ocultaban, además de luchas por parcelas de poder en materia cultural y social, rencillas de ámbito personal" (Moreno, 2008: 563). Estos contratiempos y el problema económico que supuso que varios benefactores de la representación dejaran de entregar sus aportaciones no afectaron a la salida de la revista, cuya existencia se consideró mucho más necesaria precisamente entonces -mediados de 1938-, cuando, coincidiendo con el nombramiento de Ángel Ossorio y Gallardo como embajador de la República Española en Argentina y con el multitudinario recibimiento que le tributaron a su llegada a Buenos Aires, se "inició una fase de mayor agresividad propagandística de la República en el Cono Sur” (González Calleja, 2001: 212). Orientación Española, a diferencia de Spain y de Occident, que dejaron de publicarse en 1939, continuó a la venta durante los primeros años del franquismo.

\section{Orientación Españolay Publicaciones de Estudios Hispánicos}

Al finalizar la Guerra Civil los vencedores de la contienda pudieron constatar que, aunque en España habían ganado la contienda, en Argentina habían perdido la batalla de la propaganda. Sus responsables estaban persuadidos de que la que habría de resultar verdaderamente efectiva se realizaría a partir de entonces, cuando contaran con suficientes medios (Pardo, 2011: 151), incluido el estatus diplomático del que habían carecido, lógicamente, hasta entonces. Cuando la representación oficiosa de la España franquista quedó legitimada como embajada en aquel país -que había reconocido oficialmente al Gobierno de Franco el 27 de febrero de 1939-, José Ignacio Ramos fue nombrado agregado de prensa de la legación. Su trabajo al frente de Orientación Española continuó su curso, pero también lo hicieron los problemas que habían presidido su primera etapa, acrecentados hasta alcanzar niveles ciertamente comprometidos a causa del nuevo contexto político internacional.

La promulgación en mayo de 1939 de un decreto del Gobierno de Buenos Aires "en el que se regulaba con más rigor la actuación de cualquier asociación extranjera” (Moreno, 2008: 567) obligó a 
Falange Española a actuar con precaución para evitar la prohibición de su labor en el país. A pesar de ello, iniciada la Segunda Guerra Mundial, las protestas a cuenta de las actividades que llevaban a cabo Falange y la Embajada de España en la capital argentina se sucedieron amparadas en la sospecha sostenida por Estados Unidos de que los países del Eje pudieran servirse de la España de Franco para fortalecer sus posiciones (Delgado, 1992: 147). José Ignacio Ramos intentó conciliar "las buenas maneras" de los diplomáticos y "el estilo" habitual de los falangistas, "deslumbrados por la espectacular parafernalia de los movimientos fascistas europeos a que gustaban asemejarse" (Delgado, 1992: 139), pero aquel difícil equilibrio le ocasionó problemas y enfrentamientos que pusieron en peligro en varias ocasiones su continuidad en el cargo de agregado de prensa (Moreno, 2008: 361-362), puesto que ocupó -sobreviviendo a los sucesivos cambios de embajadores y a los vaivenes de las relaciones bilaterales- hasta el final de la transición.

En 1942 -tras la salida de Ramón Serrano Súñer, el Cuñadísimo, del Ministerio de Asuntos Exteriores- el Gobierno de Madrid instó a todos sus representantes a marcar distancias con el bloque del Eje, "propiciando el acercamiento hacia los países neutrales -incluidos claro está los iberoamericanoscomo paso previo a un ulterior reconocimiento español en el escenario internacional, y buscando asimismo borrar su pasado filo-fascista" (Delgado, 1988: 91). Fue entonces cuando la Embajada de España decidió lanzar al mercado una colección de libros que vieron la luz con el sello de Ediciones de Orientación Española. Con su salida se pretendía continuar dando la batalla propagandística en favor de los valores políticos del régimen franquista a través de contenidos culturales, contenidos que resultaban aparentemente ajenos al conflicto que se dirimía en el mundo y que no eran susceptibles, por tanto, de suscitar nuevas protestas internacionales.

La decisión por la que José Ignacio Ramos se convirtió en “editor ocasional”, tal como él mismo se denominó en Biografía de mi entorno (1984: 343), no se debió, por tanto -según aseguró- a razones económicas. De acuerdo con su relato, la buena acogida dispensada a la revista Orientación Española permitió que se financiara sola gracias a "la venta, las suscripciones y la publicidad comercial" (Ramos, 1984: 344). Pero, en realidad, Orientación Española había acometido una reestructuración en 1941 con el fin de solventar los problemas económicos que generaba su escasa venta y las reticencias políticas que suscitaba su contenido. Se decidió por ello convertirla en una revista cultural dirigida a la totalidad de la América Latina, por lo que se eliminó de la cubierta el águila franquista que se había reproducido hasta entonces en todos los números. En su lugar aparecieron consignados los nuevos ámbitos de su interés: "Letras hispánicas. Doctrina social. Economía. Estadística. Bibliografía. Información” (Moreno, 2008: 580). 
Con el fin de apoyar este cambio de rumbo de la revista, José Ignacio Ramos - por iniciativa propia, según sus palabras ${ }^{15}$ o a instancias de sus superiores- inició las gestiones necesarias para sacar al mercado libros que redundaran "en defensa del buen nombre de España" y que sirvieran para reivindicar "los eternos valores hispánicos" (Ramos, 1984: 344). La solicitud de originales inéditos a varios escritores se materializó en 1942 con la publicación de El sentido misional de la conquista española, del historiador bonaerense Vicente Dionisio Sierra, futuro presidente de la Junta de Historia Eclesiástica Argentina. Aquel mismo año Ediciones de Orientación Española divulgó también una reedición de Madrid de corte a cheka, novela sobre la Guerra Civil del escritor y diplomático falangista Agustín de Foxá cuya primera edición había visto la luz en San Sebastián en 1938. Historia de la leyenda negra hispanoamericana, del historiador argentino Rómulo Carbia, apareció en 1943.

La aproximación de los ejecutivos de Buenos Aires y de Madrid que se produjo durante aquel año reavivó las sospechas sobre "la vinculación de ambos gobiernos con los manejos alemanes en el cono sur" (Delgado, 1992: 388). A principios de 1944, el descubrimiento de la existencia de una red de espionaje nazi en Argentina y de la implicación en ella de algunos franquistas obligó al embajador español a suspender la publicación de Orientación Española. José Ignacio Ramos, "que tenía fama de 'germanófilo disfrazado', estuvo a punto de ser cesado” (Delgado, 1992: 389), pero, como ya había sucedido en ocasiones anteriores, se mantuvo en su cargo, desde el que gestionó la difusión de nuevos títulos -que tal vez habían sido encargados antes de la suspensión de la revista-, libros que vieron la luz con un nuevo sello, Publicaciones de Estudios Hispánicos ${ }^{16}$. Editado por el escritor José María Castiñeira de Dios, Antecedentes hispano-medioevales de la poesía tradicional argentina, del investigador de la poesía oral argentino Juan Alfonso Carrizo, y La gesta de Roger de Flor romanceada, del que era autora la polifacética escritora bonaerense Pilar de Lusarreta, aparecieron en 1945. Un año después se publicó Formas musicales rioplatenses (cifras, estilos y milongas): Su génesis hispánica, del compositor y escritor argentino Josué Wilkes. Publicaciones de Estudios Hispánicos difundió dos títulos más que Ramos no consignó en sus memorias: Mesones y comidas en la época Cervantes (1947),

\footnotetext{
${ }^{15}$ En Biografía de mi entorno (1984), el libro de memorias de José Ignacio Ramos al que se ha hecho alusión en varias ocasiones, su autor altera el marco temporal en el que se inscriben algunas de las vivencias que refiere situando hechos que ocurrieron durante la Guerra Civil en la inmediata posguerra y viceversa. Así sucede cuando, al explicar el inicio de las ediciones que nos ocupan, asegura que los libros fueron publicados con el dinero que entregaba mensualmente el grupo de españoles que, impulsados por Vehils, permitieron la apertura y el sostenimiento de la Oficina de Prensa y Propaganda (Ramos, 1984: 344). Dichas entregas habían finalizado, en realidad, en 1939, según la documentación que ha podido analizar Mónica Quijada (1991: 198).

${ }^{16}$ El nombre de este nuevo sello editorial de la Embajada de España en Buenos Aires presenta ciertas coincidencias con el de la Central de Publicaciones Hispánicas, distribuidora que dejó de ocuparse de la venta de textos impresos españoles en Argentina y en toda Sudamérica, como había hecho en los años anteriores, a partir de 1940, siendo sustituida, a propuesta de José Ignacio Ramos, por la Compañía Importadora y Exportadora Platense (Moreno, 2008: 571).
} 
pequeño volumen escrito por el falangista Jacinto Miquelarena, corresponsal del periódico $A B C$ en Buenos Aires y buen amigo de Ramos, y Cielo y tierra. 12 horas de España (1948), del que era autor Ignacio B. Anzoátegui, la persona con la que había entablado mayor amistad en Argentina. Gracias a su ayuda, Ramos pudo realizar las ediciones referidas, una labor para la que también contó con la colaboración de Emilio Poblet, madrileño emigrado a Buenos Aires -donde fundó la Librería Académica, convertida después en la célebre Clásica y Moderna-, que fue también editor y distribuidor. Manuel Olarra, director de Espasa Calpe en aquellos años, facilitó la distribución de las obras, volúmenes de los que se hicieron tiradas de tres mil ejemplares que fueron apareciendo de forma escalonada, de suerte que la venta de un título permitía cubrir los gastos de edición del siguiente. Recuperados los costes de producción, la Embajada entregaba los ejemplares no vendidos a sus autores, con los que había acordado dicha fórmula de remuneración en sustitución del habitual desembolso de derechos (Ramos, 1984: 344-345).

Aunque fueron pocos los títulos que vieron la luz, el modelo de edición elegido resultó sumamente eficaz. Publicados sin gasto alguno, su presentación se festejó con el ofrecimiento de un vino de honor al que solían acudir algunas personalidades de la sociedad bonaerense. Se reforzaban así las labores de propaganda realizadas por el régimen, que ideó dichos actos -sobre los que informó puntualmente la prensa española ${ }^{17}$ - para hacer proselitismo de los valores y de los postulados en los que se sustentaba.

El fin de su coyuntural actividad como editor no alejó a José Ignacio Ramos del mundo del libro, al que continuó vinculado en cumplimiento de las funciones que tenía encomendadas como agregado de Prensa de la Embajada de España y, desde 1943, en calidad de corresponsal del periódico barcelonés $L a$ Vanguardia Española (Montiel, 2013), puesto que le ofreció Luis de Galinsoga, su director, tras leer con satisfacción los artículos que Ramos venía publicando, con el seudónimo de Íñigo de Santiago, en el madrileño Arriba (Ramos, 1984: 340), el periódico oficial del franquismo. Desde ese año, Ramos actuó asimismo como delegado de la Sociedad General de Autores de España para Argentina y los países limítrofes, cargo para el que fue designado por su presidente, el poeta y dramaturgo Eduardo Marquina, con quien había mantenido una estrecha relación en Buenos Aires durante la Guerra Civil (Ramos, 1984: 174-176).

\footnotetext{
${ }^{17}$ La aparición de El sentido misional de la conquista española, de Vicente Dionisio Sierra -primer volumen editado por la revista Orientación Española- se festejó el 14 de agosto de 1942 en las oficinas de la publicación. Al acto asistieron "destacados miembros de la colectividad española y numerosos intelectuales argentinos" ("Las relaciones con la Argentina". La Vanguardia Española (15-8-1942): 1 y "Mundo hispanoamericano". ABC(15-8-1942): 12). De igual modo se procedió un año después para dar a conocer Historia de la leyenda negra hispanoamericana, de Rómulo Carbia, a quien le ofrecieron un banquete al que asistieron también numerosas autoridades ("Mundo hispanoamericano". $A B C(21-8-1943)$ : 5 y "Quijotes en América". $A B C(22-8-1943): 17)$.
} 
Francisca Montiel Rayo. Ediciones propagandísticas españolas...

\section{Coda: El libro español en Argentina}

Su trabajo en dicha organización nada tenía que ver con el mundo del libro. La Sociedad General de Autores de España, que había sido fundada en 1941, únicamente gestionó desde entonces -y lo siguió haciendo hasta la refundación llevada a cabo en 1995, año a partir del cual se convirtió en la Sociedad General de Autores y Editores de España- actividades relacionadas con las artes escénicas y musicales. La eficacia con la que administraba y defendía los intereses de este sector en Sudamérica debía servir de ejemplo al mundo del libro, sugirió José Ignacio Ramos en 1946 desde las páginas de $L a$ Vanguardia Española ${ }^{18}$, donde firmó sus habituales crónicas con el seudónimo de Oriol de Montsant.

Desde su incorporación al periódico Ramos remitió a Barcelona breves notas sobre política, economía y sociedad que vieron la luz al menos una vez por semana hasta finales de la década de los setenta. En esa cabecera se divulgaron también numerosas crónicas sobre temas culturales, ámbito que el periodista frecuentó con especial interés en los primeros años del franquismo, en los que dichos asuntos se erigieron en la mejor herramienta con la que podía contar el régimen en América. La lectura de dichos artículos permite reconstruir una parte de la labor propagandística que llevó a cabo José Ignacio Ramos en la primera posguerra, una labor que se ajustó a las directrices que el Gobierno transmitió a sus representantes en el exterior, a los que se les instó a velar por "mantener los contactos existentes con sectores de la intelectualidad reaccionaria de aquellos países [y a] contestar las campañas que proclamaban que en España no quedaba nadie capaz de producir literatura ni ciencia”. Se les requirió asimismo para que trabajaran con denuedo a fin de "evitar la desaparición del libro español del mercado editorial americano" (Delgado, 1988: 88-89).

Para promocionarlo resultaba inevitable competir con la industria editorial argentina -cuya hegemonía en el mercado en lengua española era evidente-, una industria que se concentraba en la capital. Buenos Aires era desde hacía algunos años -escribió Ramos en 1949- un "remanso de exiliados de todos los países", incluidos los republicanos españoles, muchos de los cuales, como es sabido, lograron salir adelante gracias al auge que vivió el sector entonces. Oriol de Montsant apenas se refirió a ellos en las crónicas que envió a su periódico en aquel tiempo. La consigna oficial era guardar silencio, según se explicitó en el editorial que La Vanguardia Española publicó en la primera página de la edición del 10 de enero de 1945, donde se dejaba claro que la cabecera no iba a hacer ningún tipo de "propaganda directa o indirecta" de las actividades llevadas a cabo por los desterrados. "Nosotros, por lo menos", advertía el autor del texto, "nos reservamos cuidadosamente la facultad de discernir las

${ }^{18}$ Oriol de Montsant. "Los intereses hispanoargentinos en el campo editorial”. La Vanguardia Española (21-4-1946): 4. 
oportunidades para sacarles a la vergüenza pública. Lo haremos cuando convenga a la verdad de España. De ninguna manera, aunque sea para apostrofarles, cuando les convenga a ellos" ${ }^{\prime 19}$.

Por esa razón, aunque lo lógico era, como él mismo reconoció años después, que sus crónicas versaran sobre las tres principales "facetas" de la cultura -"el teatro, el cine y el libro" ${ }^{20}$, las alusiones al mundo editorial resultaron significativamente soslayadas por lo que a la presentación y al comentario de novedades bibliográficas debidas a autores españoles o que trataban sobre España se refiere. Para paliar una sequía informativa inadmisible incluso para quienes la practicaban, Ramos escribió notas propagandísticas en las que exaltó las bondades de los libros que él mismo había editado con el sello de Ediciones de Orientación Española. "Una de las obras más acabadas y perfectas nacidas de la común inquietud hispanoargentina”, escribió en 1943, era la Historia de la leyenda negra hispanoamericana, del argentino Rómulo Carbia ${ }^{21}$. A Antecedentes hispano-medioevales de la poesía tradicional argentina, de Juan Alfonso Carrizo, aparecido ya con pie de imprenta de Publicaciones de Estudios Hispánicos, se refirió a propósito de la creación en Buenos Aires del Instituto Nacional de la Tradición, del que su autor fue nombrado director, lo que le permitió iniciar su crónica con una mención al libro El paraíso y la serpiente, de José María Pemán, en el que el escritor español cantaba las excelencias de Carrizo. Editado en España, Ramos se mostraba públicamente sorprendido de que solo hubieran llegado a Buenos Aires dos ejemplares de dicho volumen "a pesar de tratarse de un interesantísimo relato de viaje por tierras argentinas"22. Con dicho apunte se refería de paso a las difíciles relaciones comerciales en materia de libros que mantuvieron en aquellos años España y Argentina, un problema del que también se ocupó en sus crónicas.

La venta de libros entre ambos países se había convertido, desde el fin de la Guerra Civil, en un conflicto latente que suscitó numerosas protestas de los respectivos gremios de editores (Larraz, 2010: 157-190). Durante los primeros años cuarenta España le compró a Argentina el 80\% de los libros que importaba (Diego, 2014: 112), lo que supuso un evidente desajuste en la balanza comercial del mercado del libro español, cuya venta en el país austral era entonces prácticamente testimonial. Llegada la hora de trabajar en favor de la recuperación del sector, la firma del acuerdo comercial hispano-argentino que se impulsó después de que Juan Domingo Perón ganara los comicios que le otorgaron la presidencia -convenio en el que el Gobierno de Madrid cifró grandes esperanzas económicas y políticas (Delgado,

19 “Nuestro eco, el vacío". La Vanguardia Española (10-1-1945): 1.

${ }^{20}$ Oriol de Montsant. "La compañía 'María Guerrero' inicia la gira por el interior”. La Vanguardia Española (8-5-1969): 54 .

${ }^{21}$ Oriol de Montsant. "Importante alegato contra la leyenda negra". La Vanguardia Española (3-8-1943), p. 4.

${ }^{22}$ Oriol de Montsant. "La poesía española revive en el cancionero popular argentino". La Vanguardia Española, (6-2-1944): 7. 
Francisca Montiel Rayo. Ediciones propagandísticas españolas...

1988: 125)- fue aprovechada para poner en marcha algunas iniciativas tendentes a revertir la situación. En ese contexto, el 21 de abril de 1946 José Ignacio Ramos celebraba públicamente que se hubiera desplazado a Buenos Aires un grupo de editores españoles para buscar soluciones. Cabía recordar, explicó Montsant orillando deliberadamente las verdaderas razones del problema, que, acabada la Segunda Guerra Mundial y normalizados poco a poco los transportes, los libros españoles iban llegando cada vez en mayor número a Argentina, pero a un precio excesivamente elevado, por lo que no podían competir con las ediciones argentinas y mexicanas ${ }^{23}$. Para solucionarlo, Ramos proponía que no se abordara el asunto desde un punto de vista comercial sino cultural, habida cuenta de que había que "velar por la pulcritud de nuestro idioma". "En igualdad de circunstancias", continuaba el periodista, "siempre el libro español ha de ser preferido en los países de nuestra habla a cualquiera otra edición continental”. El argumento esgrimido por el periodista dejaba muy claro que entre un libro editado en cualquier país americano de habla española y un libro editado en España debía potenciarse en todo momento la difusión de este último, sin duda porque consideraba que el español de España era más pulcro que el hablado en otros países.

Así se desprende también de las palabras con las que se refirió, en ese mismo artículo, a otro tema de interés, el de las traducciones, muy habituales durante la "época de oro" de la edición argentina, en la que la exportación de más de un $40 \%$ de las tiradas obligó a los editores a "proyectar catálogos más 'universales' con buena parte de la producción de literatura traducida” (Diego, 2014: 121). En opinión de Ramos, no era de recibo que las editoriales argentinas y mexicanas adquirieran rápidamente los derechos de autor de obras extranjeras para todos los países de habla española, y que, por ello, en España los lectores tuvieran que acceder a "la producción extranjera a través de traducciones plagadas de americanismos o renunciar a conocerla". "Esta situación de inferioridad debe terminar", añadión ${ }^{44}$.

En esa misma crónica José Ignacio Ramos también expresó su deseo de que pudieran llegar a España los libros publicados por editores españoles establecidos en Argentina. Pero, como era de esperar, no estaba defendiendo los intereses económicos de todas las casas editoras creadas o regentadas por ciudadanos españoles. El tratado comercial entre España y Argentina que se estaba ultimando en esas fechas, advirtió el periodista, no podía ser "tan generoso y amplio" como para convertirse en

la puerta falsa por la que entre de rondón en la península mercancía averiada. Ni las obras de chusmaje intelectual rojo exilado ni los esperpentos literarios de traductores improvisados que ni

\footnotetext{
${ }^{23}$ Desde el punto de vista político, el incremento de la venta de libros españoles en Argentina fue uno de los objetivos de la operación de expansión cultural que se puso en marcha en 1945 para contrarrestar la campaña antifranquista que tenía lugar en el ámbito internacional. El Gobierno de Franco contó con el apoyo de varios organismos, que ayudaron a idear las iniciativas que debían ponerse en marcha. También ordenó la colaboración de las legaciones diplomáticas, a las que se les pidió información para seleccionar a los libreros a los que se les enviarían libros para su venta (Delgado, 2001: 365).

${ }^{24}$ Oriol de Montsant. "Los intereses hispanoargentinos en el campo editorial”. La Vanguardia Española (21-4-1946): 4.
} 
Francisca Montiel Rayo. Ediciones propagandísticas españolas...

saben hablar castellano pueden cubrirse bajo el pabellón de una estimación hispanoargentina cuya generosidad no puede alcanzar tales extremos ni nada tiene que ver con los excelentes escritores americanos ${ }^{25}$.

Poco o nada iba a cambiar, anunciaba el periodista, para la producción de algunas casas editoras radicadas en Argentina, como él mismo demostró en sus crónicas, en las que les dedicó un tratamiento tan desigual como revelador a Sudamericana, Losada y Emecé, las tres empresas creadas en Buenos Aires durante los meses finales de la Guerra Civil. A la primera le concedió inicialmente un beneplácito tácito, como puede observarse en una de sus crónicas, publicada en 1948 con ocasión del fallecimiento de María de Maeztu -agregada cultural honoraria de la Embajada de España en Argentina-, que había redactado dos años antes el extenso prólogo que se situó al frente de la edición de La crisis del humanismo: los principios de autoridad, libertad y función a la luz de la guerra, de su hermano Ramiro, publicada por Sudamericana, aunque Ramos no mencionó entonces el nombre de la empresa ${ }^{26}$. Sí lo hizo tres años después al referirse a Miguel de Unamuno, cuyo pensamiento no dudó en utilizar a su antojo al informar de la aparición de una selección de sus ensayos -De esto y de aquello- que había sido difundida por dicha casa. "A las plumas y valores catalanes y vascos que timonea[ba]n" aquella "avisada editorial argentina" que tenía a los lectores "muy bien acostumbrados a espigar valores literarios dentro de la faramalla que tanto abunda” -escribió Ramos-, había que darles las gracias por la divulgación de este volumen ${ }^{27}$.

Para el periodista el elogio resultaba compatible con el hecho de que Sudamericana, que no tuvo en un principio "un perfil editorial nítido" (Larraz, 2010: 99), publicara, sobre todo a partir de la década de los cincuenta, numerosos títulos de autores exiliados. Pero no deja de ser curioso que no mencionara a Vehils, su fundador, a pesar de la vinculación que los unió en los días de la guerra, no en vano fue, como ha sido dicho, el creador y el gestor de la comisión que financió la OPYPRE. Tampoco aludió a su condición de benefactor de la España sublevada en sus memorias -aunque sí lo hizo en el caso de otros miembros de la citada comisión-, en las que lo recordó de forma encomiástica como presidente de la Institución Cultural Española (Ramos, 1984: 109). A la labor que había llevado a cabo en dicho organismo se refirió más ampliamente en la crónica periodística en la que dio la noticia de su fallecimiento. Destacó entonces también su condición de "generoso mecenas" de la cultura española en

\footnotetext{
${ }^{25} \mathrm{Idem}$.

${ }^{26}$ Oriol de Montsant. "Fallecimiento de la pedagoga española doña María de Maeztu”. La Vanguardia Española (8-1-1948): 5 .

${ }^{27}$ Oriol de Montsant. "Lecturas". La Vanguardia Española (10-3-1951): 9. En los primeros años del franquismo Ramos coincidió y tal vez estableció algún tipo de relación con Antonio López Llausàs, amigo del escritor Ramón Gómez de la Serna -según declaró él mismo (Oriol de Montsant. "Ramón ansía visitar Barcelona”. La Vanguardia Española (17-4-1949): 6)-, con quien Ramos mantuvo estrechos vínculos durante los años bonaerenses del creador de las greguerías, de los que dan fe la correspondencia que intercambiaron y su libro Miamigo Ramón (1980).
} 
Francisca Montiel Rayo. Ediciones propagandísticas españolas...

Argentina. Para finalizar, aludió -sin concretar en qué consistió- al "mecenazgo" que ejercieron tanto Vehils como el marqués de Foronda -vocal de la CHADE en 1936 y miembro asimismo de la comisión mencionada- "durante los años de nuestra guerra". Vehils, concluyó, "supo hacer el bien y esconder la mano" 28 .

Aunque jamás lo mencionara -tal vez a petición del propio Vehils, que pudo poner esa condición para colaborar con los sublevados durante la Guerra Civil-, Ramos no pudo olvidar la decisiva actuación del catalán, probable razón por la que tuvo una especial deferencia con la empresa que él había creado ${ }^{29}$. Muy diferente fue, en cambio, el trato que le dispensó a Losada, la casa editora fundada en 1938 por el madrileño Gonzalo Losada, responsable hasta entonces de la filial de Espasa-Calpe en Argentina, de la que salió a causa de "la inclinación franquista que había adoptado [...] durante la guerra, la cual acabó por condicionar su política de publicaciones" (Larraz, 2010: 92). En quince años Oriol de Montsant solo se refirió en una ocasión a dicho sello. Rompió su silencio sobre la editorial, a la que se hallaban vinculados no pocos exiliados republicanos y que nutría su catálogo con buena parte de sus producciones, para celebrar la concesión del primer premio del Concurso Internacional de Novelas de dicha editorial, en su edición de 1958, a La Iluminada, del escritor y abogado franquista Cecilio Benítez de Castro, que residía desde hacía una década en Buenos Aires ${ }^{30}$. Un año después, Ramos volvía a mencionar la citada editorial en una de sus crónicas, en esta ocasión para aplaudir una sentencia condenatoria por divulgar publicaciones obscenas que le había sido impuesta a Guillermo de Torre, director de la colección "Los grandes novelistas de nuestra época", y a Miguel Hernani, traductor de $E l$ reposo del guerrero, la novela editada por Losada que había sido objeto de una querella del fiscal. "Hemos entrecomillado cuidadosamente las referencias para no poner nada por nuestra cuenta", concluyó Oriol de Montsant haciendo gala de una falsa objetividad, "ya que se trata de una editorial que ha recogido frecuentemente libros zahirientes y enconados contra España” 31 .

Emecé, "la tercera gran fundación editorial en Argentina en los años 1938-1939" (Larraz, 2010: 103), que había sido impulsada por dos gallegos residentes en la ciudad y que apostó inicialmente por la publicación de obras de autores oriundos de Galicia -incluidos algunos exiliados-, fue puesta como ejemplo del esfuerzo realizado en Argentina en materia de edición en 1946, cuando la editorial había

\footnotetext{
${ }^{28}$ Oriol de Montsant. "Presencia de la poesía española”. La Vanguardia Española (24 de noviembre de 1959): 15.

${ }^{29}$ En 1965, al reseñar el fallecimiento de López Llovet, hijo de López Llausàs, Oriol de Montsant recordó que dirigía junto a su padre Editorial Sudamericana, "esta poderosa industria a la que tanto debe el libro de nuestra habla" ("Buenos Aires: Grato eco de la visita del subsecretario español de Turismo”. La Vanguardia Española (1-4-1965): 21).

30 Oriol de Montsant. “Un codiciado premio literario para un escritor español”. La Vanguardia Española (9-11-1958): 18.

31 Oriol de Montsant. “Notas porteñas”. La Vanguardia Española (2-11-1959): 16.
} 
modificado ya su línea editorial abriendo su catálogo a muchos otros autores ${ }^{32}$. Nada más pudo leerse sobre ella y sobre los títulos que publicaba en los artículos firmados por Oriol de Montsant, en los que tampoco dio cuenta de la asistencia de Camilo José Cela al Primer Congreso Mundial de Periodistas -celebrado en Santiago de Chile del 2 al 6 de diciembre de 1952-, al que Ramos asistió como representante oficial de España. En cumplimiento de sus funciones, el periodista remitió a Madrid un informe sobre el escritor gallego -con quien compartió alojamiento y actividades durante todo el encuentro (Ramos, 1984: 319-322)-, informe que sirvió para disipar todos los recelos -sin duda infundados- que había suscitado el escritor en 1951 a raíz de la publicación de su novela La Colmena en la citada Emecé (Guerrero, 2008: 27-30).

En aquel decisivo año de 1946 en el que se firmó el acuerdo comercial hispano-argentino, Ramos informó también sobre la exposición del libro español que pudo verse en Buenos Aires a propuesta del grupo de libreros que había viajado a la ciudad para promocionar las ediciones del país. Con dicha muestra, organizada por la Junta de Relaciones Culturales, se pretendía dar a conocer al público argentino la producción librera española de los últimos diez años. A la inauguración asistieron el presidente de la Cámara del Libro Español, Eva Perón, numerosas autoridades y el titular de la Embajada de España, además de los funcionarios de esta legación diplomática, que habían sido los encargados de montarla. La idea, afirmó Ramos, había sido un acierto, pero lo realmente importante a partir de ese momento era que se facilitara, "mediante un cambio editorial -análogo al turístico-, la adquisición de nuestros libros, que interés y curiosidad por ellos no falta” ${ }^{23}$.

El apoyo del régimen a los editores españoles coincidió en el tiempo con los primeras manifestaciones de la crisis de la que dio muestras el sector en Argentina a partir de 1948, crisis que pocos años después pondría fin a la "época dorada" del sector editorial vivida en los lustros precedentes. Ramos se refirió a la alarmante caída de ventas al informar a los lectores de La Vanguardia de que, a pesar de las subvenciones concedidas por el Estado, muchas editoriales tendrían que cerrar, en tanto que otras intentaban mantenerse a flote con una producción muy baja a la espera de la llegada de tiempos mejores. Para el periodista, el origen de esta grave situación se hallaba en el boom editorial que había tenido lugar en Argentina durante la Guerra Civil española y la Segunda Guerra Mundial. Proliferaron entonces -recordó el periodista- las industrias editoriales que destinaron la mayor parte de su producción a la exportación, unas ventas que resultaron muy superiores a las realizadas por España y por México porque los libros argentinos eran muy baratos. Cuando se encareció su precio a causa, entre otras razones, del cambio de divisas, se inició la crisis, una recesión que era en aquellos momentos

32 Oriol de Montsant. "Los intereses hispanoargentinos en el campo editorial”. La Vanguardia Española (21-4-1946): 7.

${ }^{33}$ Oriol de Montsant. "Interés por el libro español”. La Vanguardia Española (23-11-1946): 5. 
ciertamente alarmante ${ }^{34}$. "Las verdaderas causas de la crisis editorial argentina”, explicó Montsant el 31 de mayo de 1949 haciéndose eco del debate que se estaba produciendo en la prensa de Buenos Aires, no había que buscarlas, como se había querido hacer creer, en la situación española. "No es un secreto para nadie que entreveradas muchas de estas industrias de elementos rojos españoles”, escribió Ramos, "su influencia se hizo sentir cuando a la hora de querer echar las culpas a alguien se pensó en España como supuesta causante en buena parte de esta crisis por las supuestas dificultades que oponía a la entrada del libro argentino". Empeñado en exculpar a España -y a la política del régimen- de un problema económico cuya enorme envergadura empezaba a vislumbrarse entonces, Ramos aseguró que las causas de la situación en la que se hallaba el sector editorial en Argentina había que atribuírselas a la carestía del papel, a los salarios altos, a las tasas impuestas por otros países del continente a la hora de permitir la entrada de los libros y, en definitiva, a la crisis general que se vivía en el continente americano. Cualquier argumento que pudiera esgrimir servía para alcanzar su propósito, incluso el fin de una moda que, según aseguró, había llevado a muchos argentinos a comprar libros "para adornar vitrinas y estanterías", usanza que había permitido alcanzar récords de ventas en 1943. En realidad, las intenciones del articulista estaban bien claras, como puede observarse en su conclusión:

Y lo que a nosotros nos interesa es que comience ya a reconocerse que el libro argentino jamás tuvo la enemiga del lector español ni de nuestras autoridades, sino que han sido otras las causas de que su difusión mermase. Sin embargo, con los comentarios, notas, editoriales y artículos que se han escrito sobre estas supuestas dificultades que España ponía a la difusión del libro argentino podría hacerse un voluminoso tomo ${ }^{35}$.

Desde la Oficina de Prensa y Propaganda de la Representación de la España Nacional en Argentina, José Ignacio Ramos llevó a cabo una intensa labor durante la Guerra Civil en la que participaron también -con su apoyo económico e incluso con las gestiones que realizaron en el proceso de preparación de las ediciones- Andreu Bausili y Rafael Vehils, dos de los fundadores de Editorial Sudamericana, empresa sobre la que todavía no existe documentación suficiente que permita conocer en profundidad sus orígenes y su funcionamiento (Corte y Espósito, 2010: 260). Tampoco se han desentrañado hasta la fecha los vínculos que unieron a la bonaerense Editorial Difusión con la OPYPRE, una relación que resulta probada aunque no sea posible por el momento concretar los términos en los que se sustentó. De lo que no cabe ninguna duda es de que la Lliga Catalana -a través de algunos de los miembros más destacados de la CHADE- y la Iglesia Católica -por mano de ciertos empresarios del

${ }^{34}$ Oriol de Montsant. "El libro argentino atraviesa por una grave crisis". La Vanguardia Española (26-8-1948): 4.

35 Oriol de Montsant. "Las verdaderas causas de la crisis editorial argentina”. La Vanguardia Española (31-5-1949): 8. 
sector- actuaron de forma determinante en el desarrollo de las actividades propagandísticas relacionadas con la edición que emprendieron los sublevados en Buenos Aires.

La reconstrucción de la trayectoria profesional de Ramos, rodeada del secretismo que caracterizó al régimen al que sirvió, ilumina también los primeros años del franquismo, un tiempo en el que el periodista continuó con su apostolado, ya desde la Embajada de España, a través de la revista Orientación Española y de las ediciones homónimas, publicaciones sobre las que apenas se ha reparado hasta la fecha, lo mismo que ha sucedido con su figura, una personalidad que se esconde tras las páginas de sus memorias y de las crónicas que remitió regularmente al periódico barcelonés La Vanguardia Española, donde -por acción o por omisión- pueden vislumbrarse las líneas generales de su actuación política, un trabajo que incidió también -hasta un punto que habrá que establecer en un futuro- en la esfera de la literatura, en la del mercado editorial y en la de las relaciones comerciales hispano-argentinas durante el primer franquismo. 
Francisca Montiel Rayo. Ediciones propagandísticas españolas...

\section{Bibliografía}

Corte, Gabriela Dalla y Espósito, Fabio. "Mercado del libro y empresas editoriales entre el Centenario de las Independencias y la Guerra Civil española: la editorial Sudamericana”. Revista Complutense de Historia de América 36 (2010): 257-289.

Delgado Gómez-Escalonilla, Lorenzo (1988). Diplomacia franquista y política cultural hacia Iberoamérica, 1939-1953. Madrid: CSIC.

Delgado Gómez-Escalonilla, Lorenzo (1992). Imperio de papel. Acción cultural y política exterior durante el primer franquismo. Madrid: CSIC.

Delgado Gómez-Escalonilla, Lorenzo (2001). "La cultura como vanguardia de la política exterior: Francia, España y América Latina en la postguerra mundial”. Rolland, Denis; Delgado, Lorenzo; González, Eduardo; Niño, Antonio y Rodríguez, Miguel. L'Espagne, la France et l'Amérique Latine. Politiques culturelles, propagandes et relations internationales, XXe siècle. París: L'Harmattan: 307-401.

Diego, José Luis de (2014). “1938-1955. La ‘época de oro’ de la industria editorial”. Diego, José Luis de. Editores y políticas editoriales en Argentina (1880-2010). Buenos Aires: Fondo de Cultura Económica: 97-133.

Fabris, Mariano. "De El Pueblo a Esquiú. Modernización y regresión conservadora frente a la crisis de la prensa católica”. Itinerantes. Revista de historia y religión 3 (2013): 153-170.

González Calleja, Eduardo (2001). "Instrumentos y estrategias en tiempo de conflicto: Acción cultural y propaganda hacia América Latina”. Rolland, Denis; Delgado, Lorenzo; González, Eduardo; Niño, Antonio y Rodríguez, Miguel (dirs.). L'Espagne, la France et l'Amérique Latine. Politiques culturelles, propagandes et relations internationales, XXe siècle. París: L'Harmattan: 165-237.

González Grano de Oro, Emilio (2004). La "Otra" Generación del 27: el "Humor Nuevo" españoly "La Codorniz" primera. Madrid: Ediciones Polifemo.

Guerrero, Gustavo (2008). Historia de un encargo: "La catira» de Camilo José Cela. Literatura, ideología y diplomacia en tiempos de la Hispanidad. Barcelona: Anagrama.

Larraz, Fernando (2010). Una historia transatlántica del libro. Relaciones editoriales entre España y América Latina (1936-1950). Gijón: Ediciones Trea.

Larraz, Fernando “¿Un campo editorial? Cultura literaria, mercados y prácticas editoriales entre Argentina y España”. Cuadernos del CILHA 21 (2014): 123-136. 
Francisca Montiel Rayo. Ediciones propagandísticas españolas...

Llera, José Antonio. “Documentos inéditos sobre La Ametralladora y La Codorniz de Miguel Mihura”. Anales de Literatura Española 19 (2007): 115-135.

Massot i Muntaner, Josep (1998). Tres escriptors davant la Guerra Civil. Georges Bernanos, Joan Estelrich, Llorenç Villalonga. Barcelona: Publicacions de l’Abadia de Montserrat.

Montiel Rayo, Francisca (2013). “El exilio republicano de 1939 en las crónicas del corresponsal de $L a$ Vanguardia Española en Argentina (1943-1979)". Molinero, Carme y Tébar, Javier (eds.). VIII Encuentro Internacional de Investigadores del Franquismo. Barcelona: CEFID-UAB y Fundació Cipriano García: pp. 1-22 (edición CD-rom).

Moreno Cantano, Antonio César. “Delegaciones y oficinas de prensa españolas en el extranjero durante el primer franquismo: el caso francés (1936-1942)”. Studia histórica. Historia contemporánea 25 (2007): 265-301.

Moreno Cantano, Antonio César (2008). Los servicios de prensa extranjera en el primer franquismo (1936-1945). Madrid: Universidad de Alcalá de Henares. (tesis doctoral).

Pardo Sanz, Rosa (2011). "Diplomacia y propaganda franquista y republicana en América durante la guerra civil española”. Mateos López, Abdón y Sánchez Andrés, Agustín (eds.). Ruptura y transición. España y México, 1939. Madrid: Eneida.

Pérez Ortiz, Bernabé (1941). Por España. Buenos Aires: [s. n.].

Quijada, Mónica (1991). Aires de República, aires de cruzada: La Guerra Civil española en Argentina. Barcelona: Sendai.

Ramos, José Ignacio (1980). Mi amigo Ramón. Buenos Aires: Editorial Temas Contemporáneos.

Ramos, José Ignacio (1984). Biografía de mi entorno. Nostalgias, Recuerdos, Testimonios. Madrid/ Buenos Aires/México: Legasa.

Riquer i Permanyer, Borja de (1997). L’últim Cambó (1936-1947). La dreta catalanista davant la guerra civil y el primer franquisme. Barcelona: Eumo Editorial.

Viñas, Ángel (dir.) (2010). Al servicio de la República. Diplomáticos y Guerra Civil. Madrid: Marcial Pons Ediciones de Historia y Ministerio de Asuntos Exteriores y Cooperación. 